\title{
COMPARATIVE EVALUATION OF PHENOTYPIC RANKING DECISIONS AND TRAIT PREFERENCES OF SHEEP PRODUCERS IN AMHARA REGIONAL STATE OF ETHIOPIA
}

\author{
Godadaw MISGANAW ${ }^{\star \otimes}$, Yohannes DAGNEW and Addis GETU \\ Department of Animal Science, College of Veterinary and Animal Sciences, University of Gondar, P.O.Box 196, Gondar, Ethiopia \\ 『Email: godadaw@gmail.com; (1) ORCiD: 0000-0001-5624-7983 \\ Supporting Information
}

\begin{abstract}
This study was aimed to investigate comparative trait preferences of farmers' and selection practices for Rutana and Gumuz sheep breeds in existing production system. Ranking method, such as direct and own-flock ranking experiment with sheep keepers were carried in smallholder and large-scale production systems. Appearance, coat colour and fast growth rate were important traits in selecting breeding rams in smallholder system where as fast growth rate, tail length and appearance were preferred in large-scale system. Mothering ability, multiple births and lambing interval were most preferred for ranking breeding ewes in both systems. The mean of all objectively measured body conformation traits and body weight varies significantly across the farmers ranking categories and in line with their selection decision. In Gumuz sheep breed the average body weight of ewes which ranked as best was superior to rank as poor (34.5 kg vs. $26.7 \mathrm{~kg})$; whereas, in Rutana breed it was $39.4 \mathrm{~kg}$ vs. $29.5 \mathrm{~kg}(\mathrm{P}<0.05)$. The farmers' breeding objectives were improving reproduction, conformation and growth traits, which can increase net cash income per flock through increased number of marketable animals for meat production. Therefore, considering meat production traits is recommended as feasible strategy for future for Gumuz and Rutana sheep genetic improvement and conservation program.
\end{abstract}

Keywords: Breed improvement; Conservation; Gumuz sheep; Ranking experiment; Rutana sheep.

\section{INTRODUCTION}

Sheep productions in developing countries like Ethiopia is an important livestock farming activity and contributed immensely to the subsistence, economic and social livelihood of the smallholder farmers, in terms of generating income, meat, milk, skin and fiber (Hirpa and Abebe, 2008; Adem et al., 2018). Sheep production in developing countries is largely based on traditional breeds and characterized by diverse and multiple farmer breeding objectives (Solomon et al., 2008; Laouadi et al., 2018; Haile et al., 2019).

In Ethiopia, there are nine sheep breeds (Solomon et al., 2008) and 40 million sheep population (Central Statistical Agency of Ethiopia, 2020), which is distributed throughout the country. Despite the diverse sheep breeds in Ethiopia, the productivity and the contribution of sheep to the livelihood of resource poor farmers and the country economy is far below the potential. This might be attributed to the lack of appropriate indigenous breed improvement and utilization strategies (Solomon et al., 2011).

The local Gumuz sheep breed is prolific, adaptable to hot environmental condition and known for their tasty meat (Solomon et al., 2011). Previous study revealed that Gumuz sheep had diseases tolerance ability with a better survival rate compared with Rutana sheep, which is exist in the same area. However, it has been ranked poorly for its growth and body weight compared to the Rutana sheep (Solomon et al., 2008). Rutana sheep was introduced in the north western lowlands for crossbreeding with Gumuz as the breed is more preferable in the market and fetched higher price in the export market. Although, Gumuz sheep were preferred in terms of prolificacy and adaptation to the existing environment over Rutana and their crosses, the population of Gumuz sheep is considered decreasing in the study areas. As a consequence, the adapted local genetic resource of Gumuz breed which is the only thin-tailed breed of Ethiopia is losing its genetic diversity and considered to be declined (Solomon et al., 2008). A good understanding of production and breeding practices is fundamental to design a sound breeding program, which leads to sustainable utilization and conservation of the genetic resources (Hagos et al., 2018). Therefore, elucidating the updated comparative trait preferences of the local farmers on the two sheep breeds in the existed production systems has a paramount importance for designing effective breeding program. Breeding objectives and trait preferences can be identified through participatory approaches as advised by multiple scholars (Duguma et al., 2011; Königet al., 2016). Hence, the objective of the study was to identify the trait preferences and evaluating the selection decisions for Gumuz and Rutana sheep breeds under existing production system. 


\section{MATERIALS AND METHODS}

\section{Study area description}

The study was carried out in Metema and Quara districts of North Western Amhara regional stats, Ethiopia. The areas have an altitude range of 550-1680 m.a.s.l, mean range temperature of $22-43^{\circ} \mathrm{C}$ and mean range annual rain fall of 850-1100mm (Solomon, 2007). Based on the number of sheep maintained and flocking practice, sheep production in the area classified as smallholder and large-scale producers. Therefore, those who keep below 20 sheep in free grazing with family labor is considered as smallholder and owners that keep above 20 up to hundreds of heads of sheep in ranchbased system by using hired labor is large scale producers.

\section{Study approach}

Among the recommended participatory tools, direct ranking and own flock ranking experiment adopted from (Gemeda et al., 2010) were used to identify farmers trait preferences and selection decisions. For direct ranking a total of 240 sheep owners were randomly selected (180 from smallholder and 60 from large scale system) and used. Attributes for ewes and rams used in the own flock ranking were identified through an in-depth interview and discussion with respondents to rank the attributes in order of importance. To evaluate the selection decision of farmers, own flock ranking experiment on 40 randomly selected smallholder sheep producers and 20 large-scale were considered. Sheep owners were requested to classify their sheep into breed groups mainly based on morphology and coat colour. Within the two breed groups (Gumuz and Rutana) each owner was asked to select three ewes and rams which had lambed at least once in their flocks. Then each farmer asked to choose their best, average and poor-quality ewes and rams among the breeding ewes/rams in their flocks according to their opinion. Each owner provided at least three reasons in order of importance for the ranking ewes/rams and life history of the ranked animals were inquired and recorded. Weighting of reasons for given sets of preference was done in accordance to the farmers' ranking of importance of traits and in a similar way as done by Tadelle et al.(2012). The live body weight and some linear body measurements of the ranked animals were also taken.

\section{Data analysis}

The statistical software SPSS Ver.19 (SPSS, 2010) was used to analyze the data from participatory identification trait preferences. Owner's preference rankings were summarized into index as weighted averages. Indices were calculated for ranked variables (selection criteria). Index was computed using the following formula as suggested by Kosgey et al. (2008). Sum of (3x for rank $1+2 x$ for rank $2+1 x$ for rank 3) given for a given reason divided by the sum of (3x for rank $1+2 x$ for rank $2+1 x$ for rank 3) for overall reasons. Body condition score (BSC) was done for the experimental sheep. As indicated by Yohannes et al. (2018) a scored between 1 and 5, where $1=$ very thin; $2=$ thin, $3=$ medium, 4 = fat, 5 = very fat was used. The body weight and other linear body measurements were analyzed by the general linear model (GLM) procedure of SAS (2009). Weighted ranking methodology was applied for choosing between alternatives with multiple attributes in decision-making. Reasons 1-3 and sum of weighted ranks (Sum) and relative weights (Rel.weights) as proportion of the total Sum by breed and system adopted from (Bangweon and Seokjoong, 2016).

\section{RESULTS AND DISCUSSION}

\section{Selection criteria for ranking of breeding ram}

The farmers' selection criteria for breeding rams are presented in Table 1. Perusal of these results showed that first four selection criteria for rams, in descending order, were body conformation, coat colour, growth rate and tail length under small holder system whereas body conformation, growth rate and coat colour / tail length under large scale system. In both smallholder and large-scale production system, conformation trait receives high emphasis for ranking of breeding rams for both breeds. The principal reason why smallholder farmers ranked body conformation as first criteria to select a breeding ram was possibly their belief that well conformed ram showed good breeding potential and fetched better sale price in the market. Ranked traits for selection of breeding ram in this study was similar with earlier results of Solomon et al. (2010) and Nigussieet al. (2015) for indigenous sheep in central and Eastern Ethiopia. Next to body conformation smallholder farmers give high attention to colour as selection criteria for breeding ram. Hence, males with red and patchy of red and white colours were selected. This may due to preference of white or red colored in high demand for religious festival and have high local market values in comparison with pure black or unwanted coat colour. A previous study by Edea et al. (2012) on Bonga and Horro sheep breeds confirmed that beauty traits like coat colour might be associated with socio-cultural practices and market demand. At the same time, Nigussieet al. (2015) also reported that coat colour was the second ram ranking trait in crop-livestock production system for indigenous sheep breed in Eastern Ethiopia. In large scale production system, growth rate of lambs was the second selection criteria for ranking of best rams in both breeds. The reason why growth trait was used in large scale system is related with the producer's primary aim of production and level of awareness. This means that large scale producers are more commercial and market oriented than small scale producers that kept sheep for their subsistence. Therefore, large scale producers mainly targeted to utilize the 
border advantage and sale sheep to Sudanese traders who prefer a yearling male lamb. Hence, large scale produces needs to reared lambs, which can reach market weight sooner. Similar findings were reported by Nugussieet al. (2015) and Abebeet al. (2020) for indigenous sheep in Ethiopia, and Sheriff et al. (2021) for Arab and Oromo goat keepers in north western Ethiopia. According to their justification, the high attribute of fast growth of lambs and kids for breeding and meat production might due to high market demand and the proximity of the study areas to export market.

Table 1 - Selection criteria for ranking of breeding rams in smallholder and large-scale system

\begin{tabular}{|c|c|c|c|c|c|c|c|c|c|}
\hline \multirow{2}{*}{ Selection Criteria } & \multicolumn{4}{|c|}{ Smallholder system } & \multicolumn{4}{|c|}{ Large scale system } & \multirow{2}{*}{$\begin{array}{c}\text { Overal } \\
\text { I }\end{array}$} \\
\hline & $\mathbf{R 1}$ & R2 & R3 & I & $\mathbf{R 1}$ & $\mathbf{R 2}$ & R3 & I & \\
\hline Body conformation & 44.4 & 17.2 & 21.7 & 0.32 & 15.0 & 26.7 & 13.3 & 0.19 & 0.26 \\
\hline Coat color & 9.4 & 30.6 & 35.0 & 0.21 & 13.3 & 10.0 & 25.0 & 0.14 & 0.17 \\
\hline Growth rate & 22.8 & 16.1 & 7.8 & 0.18 & 26.7 & 20.0 & 21.7 & 0.24 & 0.21 \\
\hline Libido & 5.6 & 15.0 & 7.2 & 0.09 & 13.3 & 16.7 & 13.3 & 0.14 & 0.11 \\
\hline Age at $1^{\text {st }}$ mating & 3.9 & 8.3 & 10.0 & 0.06 & 10.0 & 8.3 & 10.0 & 0.09 & 0.08 \\
\hline Tail length & 13.9 & 12.8 & 18.3 & 0.14 & 21.7 & 18.3 & 16.7 & 0.20 & 0.17 \\
\hline
\end{tabular}

\section{Selection criteria for ranking of breeding ewes}

As indicated in Table 2, body conformation was reported as the first selection criteria of breeding ewes in both production systems. Multiple births, mothering ability and lambing interval were ranked descending as the next three selection criteria of breeding ewes in large scale production system. Whereas mothering ability, multiple births and coat color were orderly ranked in smallholder production system. Previous study reported that mothering ability increases the chance of survival of young goats (Snyman, 2010; Tesema et al., 2020) and mainly given high emphasis by farmers in selecting breeding ewes, which is in support of the current study. The main reason why sheep farmers selecting ewes with good mothering abilities is by considering of the caring and nourishing potential of ewes for better growth and survival of lambs. This result is in agreement with Dugumaet al. (2011) reported that there was a high choice preference for good mothering ability of ewes in four indigenous sheep breeds of Ethiopia by anticipating a healthy and good-sized lamb in their flock. Hence, the high preference of ewes mothering quality might be the indication sheep producers are trying to be profitable by obtaining market demanded and large sized lambs in early ages. In agreement to this, Abebeet al. (2020) indicated that one possible reason of smallholder farmers for selecting of ewes with sound mothering abilities could be selling lambs for income generation, thus well-nourished lambs are expected to fetch a better price. In large scale production system of this study, twining ability was the second most important trait for ranking of breeding ewes. The higher preference for twinning was consistent with the reports of Edea et al. (2012) for Bonga sheep and Nziku et al. (2016) for dairy goats in Kenya.

Table 2 - Selection criteria for ranking of breeding ewes in smallholder and large-scale system

\begin{tabular}{|c|c|c|c|c|c|c|c|c|c|}
\hline \multirow{2}{*}{ Selection Criteria } & \multicolumn{4}{|c|}{ Smallholder system } & \multicolumn{4}{|c|}{ Large scale system } & \multirow{2}{*}{$\begin{array}{c}\text { Overall } \\
\text { I }\end{array}$} \\
\hline & $\mathbf{R 1}$ & $\mathbf{R 2}$ & R3 & I & R1 & R2 & R3 & I & \\
\hline Body conformation & 23.3 & 21.7 & 8.3 & 0.20 & 33.3 & 10.0 & 20.0 & 0.23 & 0.22 \\
\hline Coat colour & 13.3 & 16.1 & 22.2 & 0.16 & 6.7 & 10.0 & 8.3 & 0.08 & 0.12 \\
\hline Mothering ability & 20.6 & 16.1 & 20.6 & 0.19 & 3.3 & 16.7 & 30.0 & 0.12 & 0.16 \\
\hline Age at $1^{\text {st }}$ lambing & 5.0 & 7.2 & 3.9 & 0.06 & 11.7 & 15.0 & 10.0 & 0.13 & 0.09 \\
\hline Twinning ability & 12.2 & 22.2 & 16.1 & 0.16 & 15.0 & 28.3 & 13.3 & 0.19 & 0.17 \\
\hline Lambing interval & 18.9 & 8.9 & 8.3 & 0.13 & 25.0 & 18.3 & 5.0 & 0.19 & 0.16 \\
\hline lamb growth & 6.7 & 7.8 & 20.6 & 0.10 & 5.0 & 1.7 & 13.3 & 0.05 & 0.08 \\
\hline
\end{tabular}

\section{Evaluation of farmers ranking decision}

As indicated in table 3 , there was a significant difference $(P<0.001)$ in the mean values for morph-metric conformation traits across the established ranking groups. Among all ewes and rams studied within the two production systems, those selected as best were highest for all traits than those grouped as poor.

In general, the ewes and rams grouped as average had mean values that were in between the best and poor groups. For instance, in smallholder system, the difference between the best and poor group in live weight for Gumuz sheep was $8.2 \mathrm{~kg}$ at two years age. Rams ranked as best in both breed groups were higher in all measured traits compared with rams classified as poor qualities (Table 3). For instance, in Gumuz rams the magnitude difference between the best and inferior rams in live weight, body condition and scrotal circumference were $12.7 \mathrm{~kg}, 0.9$ and $3.2 \mathrm{~cm}$, respectively. In Rutana ram, the differences between the two groups were $13 \mathrm{~kg}$ of live weight, 1.8 body condition and $1.9 \mathrm{~cm}$ scrotal circumferences.

In the present study, there was significant difference between breeds and ranks for all objectively measured traits, which were in accordance with those reported by Gemeda et al. (2010) and Königet al. (2016). Rutana ewes and rams had higher mean values for all traits compared with Gumuz rams and ewes. In addition, in both breeds ewes and rams 
selected as best significantly superior than with that of ranked as poor in all of measured body conformation traits. Inline to this, Sheriff et al. (2021) for Arab and Oromo goat keepers in north western Ethiopia and Getachewet al. (2020) for indigenous goat of the pastoral communities in Ethiopia justified that the mean values of does ranked as best and poor quality, there were clear and logical differences in most of the attributes considered. At the same time, a recent study on Simien sheep breed showed that the best ranked ewes had significantly higher values than the other ranked groups (Solomon et al., 2020). In general, there was a clear trend for the different traits of ewes and rams ranked from best to inferior. Therefore, using of farmers knowledge for selecting the best animals is possible option to start the breeding program where performance recording totally lacking.

Table 3 - Least squares mean ( \pm SE) of objectively measured traits by breed types and rank categories

\begin{tabular}{|c|c|c|c|c|}
\hline Trait & Breed & Rank & LS (mean \pm SE) Ewes & LS (mean \pm SE) Rams \\
\hline \multirow{6}{*}{ Body Weight (kg) } & \multirow{3}{*}{ Gumuz } & Best & $34.5 \pm 3.3^{a}$ & $40.1 \pm 6.1^{\mathrm{a}}$ \\
\hline & & Average & $30.2 \pm 4.0^{b}$ & $30.2 \pm 4.5^{b}$ \\
\hline & & Poor & $26.7 \pm 4.7^{c}$ & $27.4 \pm 2.6^{c}$ \\
\hline & \multirow{3}{*}{ Rutana } & Best & $39.4 \pm 5.7^{d}$ & $41.4 \pm 8.2^{d}$ \\
\hline & & Average & $35.1 \pm 5.0^{e}$ & $34.5 \pm 4.1^{\mathrm{e}}$ \\
\hline & & Poor & $29.5 \pm 6.2^{f}$ & $28.4 \pm 5.4^{f}$ \\
\hline Significance level & $\star \star *$ & $\star * *$ & & \\
\hline \multirow{6}{*}{ Heart Girth $(\mathrm{cm})$} & \multirow{3}{*}{ Gumuz } & Best & $77.1 \pm 3.3^{a}$ & $78.5 \pm 4.3^{a}$ \\
\hline & & Average & $74.2 \pm 3.4^{b}$ & $73.2 \pm 3.9^{b}$ \\
\hline & & Poor & $71.4 \pm 3.1^{c}$ & $73.1 \pm 5.1^{c}$ \\
\hline & \multirow{3}{*}{ Rutana } & Best & $82.5 \pm 4.1^{d}$ & $86.4 \pm 7.3^{d}$ \\
\hline & & Average & $79.1 \pm 3.9^{e}$ & $78.7 \pm 4.9^{e}$ \\
\hline & & Poor & $76.2 \pm 4.2^{f}$ & $75.1 \pm 5.6^{f}$ \\
\hline Significance level & $\star * *$ & $\star \star *$ & & \\
\hline \multirow{6}{*}{ Body Length (cm) } & \multirow{3}{*}{ Gumuz } & Best & $68.8 \pm 2.7^{a}$ & $69.0 \pm 3.9^{a}$ \\
\hline & & Average & $66.3 \pm 2.9^{b}$ & $65.6 \pm 4.0^{b}$ \\
\hline & & Poor & $63.7 \pm 3.1^{c}$ & $65.4 \pm 3.5^{c}$ \\
\hline & \multirow{3}{*}{ Rutana } & Best & $71.1 \pm 3.6^{d}$ & $73.0 \pm 5.4^{d}$ \\
\hline & & Average & $67.7 \pm 3.4^{e}$ & $67.3 \pm 4.7^{e}$ \\
\hline & & Poor & $64.9 \pm 3.7^{f}$ & $64.6 \pm 4.3^{f}$ \\
\hline Significance level & $\star * *$ & $\star * *$ & & \\
\hline \multirow{6}{*}{ Wither Height (cm) } & \multirow{3}{*}{ Gumuz } & Best & $68.9 \pm 3.4^{a}$ & $73.4 \pm 8.5^{a}$ \\
\hline & & Average & $64.7 \pm 4.8^{b}$ & $68.1 \pm 6.1^{b}$ \\
\hline & & Poor & $61.6 \pm 5.1^{c}$ & $69.3 \pm 4.0^{c}$ \\
\hline & \multirow{3}{*}{ Rutana } & Best & $77.6 \pm 4.8^{d}$ & $79.5 \pm 5.5^{d}$ \\
\hline & & Average & $73.9 \pm 3.8^{e}$ & $72.7 \pm 4.8^{\mathrm{e}}$ \\
\hline & & Poor & $71.6 \pm 3.2^{f}$ & $69.5 \pm 5.1^{\mathrm{cf}}$ \\
\hline Significance level & $\star \star \star$ & $\star *$ & & \\
\hline \multirow{6}{*}{ Body Condition Score } & \multirow{3}{*}{ Gumuz } & Best & $3.2 \pm 0.4^{a}$ & $3.2 \pm 0.8^{a}$ \\
\hline & & Average & $2.4 \pm 0.5^{b}$ & $2.7 \pm 0.5^{b}$ \\
\hline & & Poor & $1.6 \pm 0.4^{c}$ & $2.3 \pm 0.3^{c}$ \\
\hline & \multirow{3}{*}{ Rutana } & Best & $4.0 \pm 0.6^{d}$ & $3.7 \pm 0.8^{d}$ \\
\hline & & Average & $3.0 \pm 0.4^{e}$ & $2.6 \pm 0.5^{e}$ \\
\hline & & Poor & $2.3 \pm 0.4^{f}$ & $1.9 \pm 0.6$ \\
\hline Significance level & *** & *** & & \\
\hline \multirow{6}{*}{$\begin{array}{l}\text { Scrotal Circumference } \\
(\mathrm{cm})\end{array}$} & \multirow{3}{*}{ Gumuz } & Best & & $26.1 \pm 3.4^{a}$ \\
\hline & & Average & & $22.7 \pm 3.1^{b}$ \\
\hline & & Poor & & $22.9 \pm 2.5^{b}$ \\
\hline & \multirow{3}{*}{ Rutana } & Best & & $25.5 \pm 3.2^{\mathrm{d}}$ \\
\hline & & Average & & $23.7 \pm 3.7^{e}$ \\
\hline & & Poor & & $23.6 \pm 2.6^{e}$ \\
\hline Significance level & * & * & & \\
\hline
\end{tabular}

\section{Trait preferences of farmers}

Reproduction (lambing interval and twining abilities) and mothering ability were equally the second important traits for appreciated Gumuz ewes in large scale system. The highest weighted reasons reported for Rutana ewes were for appreciating their body size and growth (0.32) in large scale system and, for mothering abilities and body size and growth (equally 0.28 ) in smallholder system (Table 4). Body condition and reproduction were the second and the third preferred traits in the same breed and production system. Breed behavior was the last preferred trait in both breeds and production systems. 
Reproduction, mothering ability, body size and growth were the most preferred traits for appreciating Gumuz and Rutana ewes in both production systems. This is in agreement with previous studies reported by Solomon et al. (2011) in the same area for the same breed. Inclusion of reproductive traits in designing a breeding program is, however, reasonable as the trait should reflect owners' preferences and will make them more beneficiaries from the sheep production system. Sheep owners' positive view on body size has direct effect in the production of marketable animals with good body conformation, which are later affect to their market price. Higher preference values of body size for breeding animals were reported by many previous studies in Ethiopia (Solomon et al., 2010; Duguma et al., 2011; Solomon et al., 2011). Mothering ability for Rutana sheep in both production systems also considered as the second most important trait in identifying best ewes.

\section{Table 4 - Smallholder and commercial farmers' ewe trait preference}

\begin{tabular}{|c|c|c|c|c|c|c|c|c|c|c|c|c|}
\hline \multirow{3}{*}{ Breed and Trait } & \multicolumn{6}{|c|}{ Smallholder } & \multicolumn{6}{|c|}{ Large scale } \\
\hline & \multicolumn{3}{|c|}{ Reasons } & \multirow{2}{*}{ Sum } & \multirow{2}{*}{ Rel. wt } & \multirow{2}{*}{ Rank } & \multicolumn{3}{|c|}{ Reasons } & \multirow{2}{*}{ Sum } & \multirow{2}{*}{ Rel.wt } & \multirow{2}{*}{ Rank } \\
\hline & 1 & 2 & 3 & & & & 1 & 2 & 3 & & & \\
\hline \multicolumn{13}{|l|}{ Gumuz } \\
\hline Body size and growth & 10 & 6 & 4 & 20 & 0.17 & 2 & 4 & 3 & 5 & 12 & 0.20 & 1 \\
\hline Body condition & 8 & 5 & 4 & 17 & 0.14 & 4 & 3 & 3 & 2 & 8 & 0.13 & 4 \\
\hline Mothering abilities & 9 & 5 & 6 & 20 & 0.17 & 2 & 5 & 2 & 2 & 10 & 0.17 & 2 \\
\hline Reproduction & 12 & 8 & 6 & 26 & 0.22 & 1 & 5 & 5 & 0 & 10 & 0.17 & 2 \\
\hline Drought Tolerance & 4 & 4 & 7 & 15 & 0.13 & 5 & 3 & 2 & 3 & 8 & 0.13 & 4 \\
\hline Disease Resistances & 11 & 1 & 6 & 18 & 0.15 & 3 & 2 & 3 & 4 & 9 & 0.15 & 3 \\
\hline Breed behavior & 0 & 1 & 3 & 4 & 0.03 & 6 & 1 & 2 & 0 & 3 & 0.04 & 5 \\
\hline \multicolumn{13}{|l|}{ Rutana } \\
\hline Body size and growth & 14 & 11 & 8 & 33 & 0.28 & 1 & 5 & 7 & 7 & 19 & 0.32 & 1 \\
\hline Body condition & 6 & 3 & 9 & 18 & 0.15 & 2 & 2 & 4 & 1 & 7 & 0.11 & 4 \\
\hline Mothering ability & 8 & 14 & 11 & 33 & 0.28 & 1 & 6 & 4 & 2 & 12 & 0.21 & 2 \\
\hline Reproduction & 8 & 4 & 5 & 17 & 0.14 & 3 & 4 & 2 & 4 & 10 & 0.16 & 3 \\
\hline Drought Tolerance & 1 & 2 & 2 & 5 & 0.05 & 5 & 0 & 1 & 3 & 4 & 0.06 & 6 \\
\hline Disease Resistances & 2 & 2 & 5 & 9 & 0.07 & 4 & 2 & 2 & 1 & 5 & 0.09 & 5 \\
\hline Breed behavior & 2 & 2 & 0 & 4 & 0.03 & 6 & 1 & 1 & 1 & 3 & 0.05 & 7 \\
\hline
\end{tabular}

\section{CONCLUSION}

Smallholder farmers primarily selected body conformation with ability to give multiple births and decent mothering ability whereas; multiple births and lambing interval were important selection criteria by large scale producers for breeding ewes. Physical appearance traits like body conformation and growth rate were principally considered for selection of breeding rams in both production systems. In general, traits, which have direct influence on the market price,are highly marked as a selection criterion for breeding rams and ewes. The top three preferred traits according to the weighted rank values were reproduction, body size and mothering ability. The main breeding goals for both systems have been defined as increasing meat production and marketed animals. This implies that designing sheep improvement strategy in the area should primarily target towards meat production traits.

\section{DECLARATIONS}

Corresponding author

E-mail: godadaw@gmail.com

Authors' contribution

All of authors contribute on idea conception, data collection and analysis, and the write up of the manuscript.

\section{Conflict of interests}

The authors have not declared any conflict of interests.

\section{Acknowledgements}

We are grateful to the farmers in Metema and Quara districts who participated in the study. The University of Gondar funded the study and we are grateful for that financial support. Besides, we are thankful for Meseret Molla, Friehiwot Alemu and Emebet Negesse for their cooperation in study approach design, data collection and organization. 


\section{REFERENCES}

Abebe AS, Alemayehu K, Johansson AM and Gizaw S (2020). Breeding practices and trait preferences of smallholder farmers for indigenous sheep in the northwest highlands of Ethiopia: Inputs to design a breeding program. PLoS One, 15(5): e0233040. Article Link

Adem M, Tadele E, Mossie H, and AyenalemM (2018). Income diversification and food security situation in Ethiopia: A review study. Cogent Food \& Agriculture, 4(1): 1513354. Article link

Bangweon S and Seokjoong K (2016).A Method of Assigning Weights Using a Ranking and Non-hierarchy Comparison.Advances in Decision Sciences, 2016: Article ID: 8963214. Article link I DOI: https://doi.org/10.1155/2016/8963214

Central Statistical Agency of Ethiopia (CSA) (2020).Agricultural Sample Survey 2019/20 [2012 E.C.]. Volume II report on livestock and livestock characteristics (private peasant holdings). Central Statistical Agency (CSA): Addis Ababa, Ethiopia. Article link

Duguma G, Mirkena T, Haile A, Iñiguez L, Okeyo AM and Markos M (2011). Identification of smallholder farmers' and pastoralists' preferences for sheep breeding traits: choice model approach. Animal, 5:1984-1992. Article link

Edea Z, Aynalem H, Markos T, Sharma AK, Solkner J and Wurzinger M (2012). Sheep production systems and breeding practices of smallholders in western and south-western Ethiopia: Implications for designing community-based breeding strategies. Livestock Research for Rural Development, 24(3): Article \#117. Article link

GetachewT, Haile A, Tessema T, Dea D, Edea Z and Rischowsky B (2020). Participatory identification of breeding objective traits and selection criteria for indigenous goat of the pastoral communities in Ethiopia.Tropical Animal Health and Production, 52(4): 2145-2155. DOI: https://doi.org/10.1007/s11250-020-02243-4

Gemeda D, Mirkena T, Haile A, Iñiguez L, Okeyo AM and Markos M (2010). Participatory approaches to investigate breeding objectives of livestock keepers. Livestock Research for Rural Development, 22 (4): Article \#64. Article link

Hagos A, Solomon G and Mengistu U (2018).Identification of breeding objectives for Begait goat in western Tigray, North Ethiopia.Tropical Animal Health and Production, 50(2):1887-1892. DOI: https://doi.org/10.1007/s11250-018-1640-5

Haile A, Gizaw S, Getachew T, Mueller JP, Amer P, Rekik M, and Rischkowsky B (2019). Community-based breeding programmes are a viable solution for Ethiopian small ruminant genetic improvement but require public and private investments. Journal of Animal Breeding and Genetics, 136(5): 319-328. Article link I DOI: https://doi.org/10.1111/jbg.12401

Hirpa A and Abebe G (2008).Economic Significance of Sheep and Goats. Sheep and Goat Production Hand book of Ethiopia. pp. 325-340. Article link

König EZ, Mirkena T, Strandberg E, Audho J, Ojango J, Malmfors B and Okeyo A.M (2016). Participatory definition of breeding objectives for sheep breeds under pastoral systems. The case of Red Maasai and Dorper sheep in Kenya.Tropical Animal Health and Production, 48(1):9-20. DOI: https://doi.org/10.1007/s11250-015-0911-7

KosgeyIS, Rowlands GJ, Arendonk JAM and Baker RL (2008). Small ruminant production in smallholder and pastoral/extensive farming systems in Kenya. Small Ruminant Research, 77(3):11-24. Article link DOI: https://doi.org/10.1016/i.smallrumres.2008.02.005

Laouadi M, Tennah S, Kafidi N, Antoine-Moussiaux N, Moula N (2018). A basic characterization of small-holders' goat production systems in Laghouat area, Algeria. Pastoralism, 8(1):1-8. Article link I DOI: https://doi.org/10.1186/s13570-018-0131-7

Nigussie H, Mekasha Y, Kebede K, Abegaz S and Kumar PS (2015). Indigenous sheep production system in eastern Ethiopia: Implications for genetic improvement and sustainable use. American Scientific Research Journal for Engineering, Technology, and Sciences, 11(1): 136-152. Article link

Nziku ZC, KIfaro GC, Eik C, Steine T and Ådnøy T (2016).Reasons for keeping dairy goats in Tanzania, and possible goals for a sustainable breeding program.Animal Production Science, 57 (1):338-346. Article link

SAS (2009). Statistical Analysis System: SAS/STAT Users Guide, version 9.1., SAS Institute Inc., Cary, NC, USA.

Sheriff 0 , Alemayehu $K$ and Haile A (2021). Phenotypic ranking experiments in identifying breeding objective traits of smallholder farmers in northwestern Ethiopia. PLoS ONE, 16(3): e0248779. Article link I DOI: https://doi.org/10.1371/journal.pone.0248779

Snyman MA (2010). Factors affecting pre-weaning kid mortality in South African Angora goats. South African Journal of Animal Science, 40(1): 54-64. Article link I DOI: https://doi.org/10.4314/sajas.v40i1.54128

Solomon A, Alayu K, Samrawit T, Tsegaye A, Yosef A and Belete S (2020). Participatory Identification of Breeding Objective Traits and Optimizing Community Based Breeding Program for Simien Sheep in the Highlands of North Gondar. In: Proceedings of the 12th Annual Regional Conference on Completed Livestock Research Activities Bahir Dar, Ethiopia, May, 13 - 16, 2020.

Solomon A (2007). In-situ characterization of Gumuz sheep under farmers' management in north-western lowlands of Amhara region. M.Sc. Thesis. Haramaya University, Ethiopia. Article Link

Solomon G, Getachew T, Edea Z, Mirkena T, Duguma G and Tibbo M (2011). Characterization of the indigenous breeding strategies of sheep farming communities in Ethiopia: A basis for designing community-based breeding programs. ICARDA Research Report.Aleppo, Syria, ICARDA. Article link

Solomon G, Komen H and Arendonk JAM (2010). Participatory definition of breeding objectives and selection indexes for sheep breeding in traditional systems.Livestock Science, 128:67-74. DOI: https://doi.org/10.1016/j.livsci.2009.10.016 
Solomon G, Komen H, Hanotte $\mathrm{O}$ and Arendonk JAM (2008). Indigenous sheep resources of Ethiopia: types, production systems and farmers preferences. Animal Genetic Resources Information, 43(2):25-40. Article Link I DOI: http://dx.doi.org/10.1017/S1014233900002704

SPSS (2010).Software user's guide.Version 19.

Tadelle M, Duguma G, Willam A, Wurzinger M, Haile A and Rischkowsky B (2012). Community-based alternative breeding plans for indigenous sheep breeds in four agro-ecological zones of Ethiopia. Journal of Animal Breeding and Genetics, 129:244-253. PMID: 22583329 I DOI: https://doi.org/10.1111/j.1439-0388.2011.00970.x

Tesema Z, Alemayehu K, Kebede D, Getachew T, Deribe B, Taye M, and YizengawL (2020). Genetic analysis of survival potential of Boer $x$ Central Highland goats under semi-intensive management. Small Ruminant Research, 193: 106253. DOI: https://doi.org/10.1016/i.smallrumres.2020.106253

Yohannes D, Solomon G, Mengistu U and Yoseph T (2018).Growth Performance of Gumz, Rutana and Gumz-Rutana Crossbred Sheep under On-Farm conditions in Northwestern Lowlands of Amhara Region, Ethiopia.East African Journal of Veterinary and Animal Sciences. 2 (1): 57-66. Article link 